\title{
Compressive Strength Improvement and Water Permeability of Self-Healing Concrete Using Bacillus Subtilis Natto
}

\author{
Nguyen Ngoc Tri Huynh ${ }^{1}$, Kei-ichi Imamoto ${ }^{2}$, and Chizuru Kiyohara ${ }^{3}$ \\ ${ }^{1}$ Department of Architecture, Tokyo University of Science (TUS), Japan, nnthuynh@hcmut.edu.vn \\ Department of Silicate Materials, Viet Nam National University Ho Chi Minh City (VNUHCM), Ho \\ Chi Minh City University of Technology (HCMUT), Vietnam \\ ${ }^{2}$ Department of Architecture, Tokyo University of Science (TUS), Japan, imamoto@rs.kagu.tus.ac.jp \\ ${ }^{3}$ Department of Architecture, Tokyo University of Science (TUS), Japan, ckiyo@rs.tus.ac.jp
}

\begin{abstract}
In recent years, many projects have been carried out to enhance the durability of concrete structure from the influence of cracks. Generally, managing cracks should be a rather preventative method for sustainable development. Based on that, Bacillus subtilis natto - a local bacterium in Japan was found to have the ability to form $\mathrm{CaCO}_{3}$, which can be used as healing materials for cracks in the concrete structure. The bacterial biomineralization immobilized in lightweight aggregate was studied to improve the compressive strength by healing the cracks and densifying the structure. Moreover, as an essential parameter for durability enhancement, the water permeability of self-healing concrete through a water-flow system was carried out. Experimental results on the behavior of the materials indicate that Bacillus subtilis natto could lead the compressive strength to $40 \%$ higher than the controls. Promising result in preventing the water through the cracks confirmed the self-healing effect with more potential in larger-scale.
\end{abstract}

Keywords: Self-Healing Concrete, Calcium Carbonate, Crack, Bacteria, Bacillus Subtilis Natto.

\section{Introduction}

Although concrete is probably the most commonly used construction material, cracking in concrete structure has been experienced by both the research community and the industrial engineers. Cracking can lead to many problems, such as water leakage and reinforcement corrosion. For many years, although various repairing methods have been developed with deliberate external intervention, it is difficult in the case of the micro-cracks or cracks embedded deep in concrete structures. Therefore, an automated method to repair cracks is necessary for sustainable concrete infrastructure. Hence, bacteria-based self-healing concrete can be a promising solution to extend the service life and durability of concrete structures. According to previous studies, limited strains of bacteria can be used for self-healing concrete, such as Bacillus cohnii (Jonkers, 2007), Bacillus pasteurii (Ramachandran et al., 2001), Bacillus pseudofirmus (Jonkers and Schlangen, 2008), Bacillus subtilis (Matsushita et al., 2010; Huynh et al., 2017).

In this study, Bacillus subtilis natto - Japanese microorganism was selected and applied with a suitable proportion of nutrients to form $\mathrm{CaCO}_{3}$ and prevent adverse effects on concrete durability. Based on the urea hydrolysis, bacteria become negatively charged, leading to the rapid attraction of surrounding calcium ions for the biomineralization. Also, bacteria can degrade organic compounds included lactose, as a carbon source for growth and activation. 
These processes controlled the adverse effects of nutrients on the properties of fresh and hardened concrete. Moreover, the cement matrix and concrete structure can be enhanced by the densifying process with the generation of $\mathrm{CaCO}_{3}$ and bacterial bioproducts, associated with the high mechanical resistance and high ability of water permeability. Besides, Bacillus subtilis natto does not cause disease (Brenner and Miller, 2014), and almost safe to work within the laboratory. Moreover, Bacillus subtilis natto would be an economical solution because of the low cost of bacteria spores, compared to the other microorganisms. We aimed to evaluate the strength improvement as well as the self-healing ability of concrete specimens with the bacteria immobilized in lightweight aggregate as a mixture component. This technique was expected to improve the self-healing capacity and extend the life span of bacteria. In addition, the water permeability of self-healing concrete was also investigated by a water-flow testing system.

\section{Materials and Experiments}

\subsection{Compressive Strength Improvement Using Bacterial Lightweight Aggregate}

Table 1. Mixture proportion and materials properties for $1 \mathrm{~m}^{3}$ of concrete.

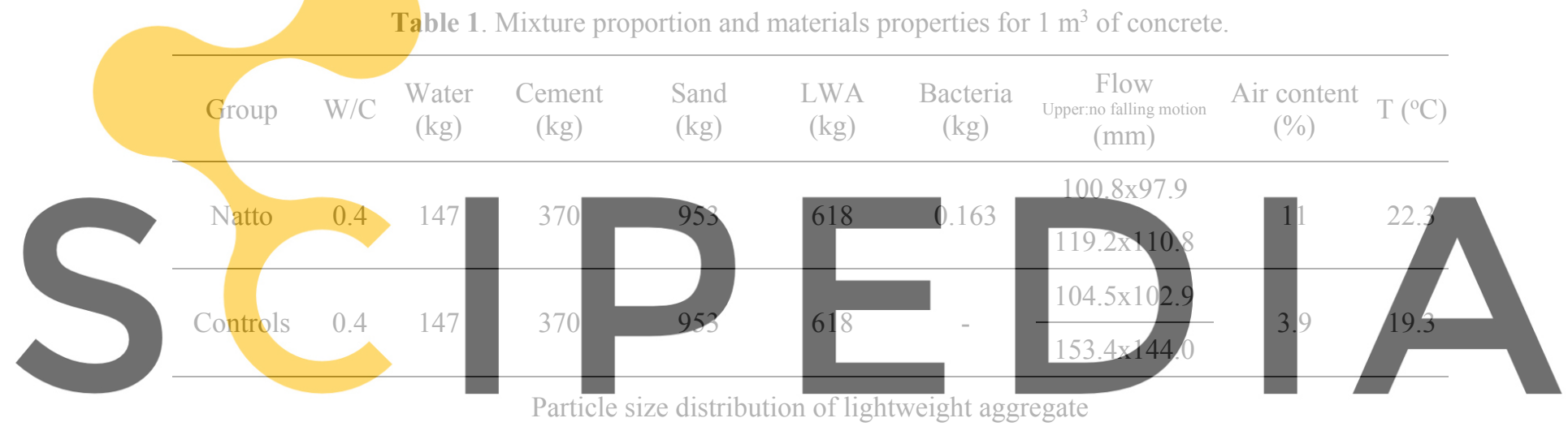

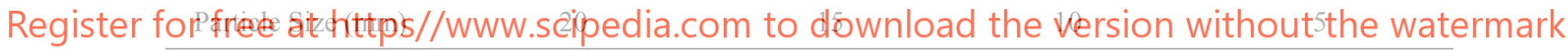
Percent passing $(\%)$ 100 99 47
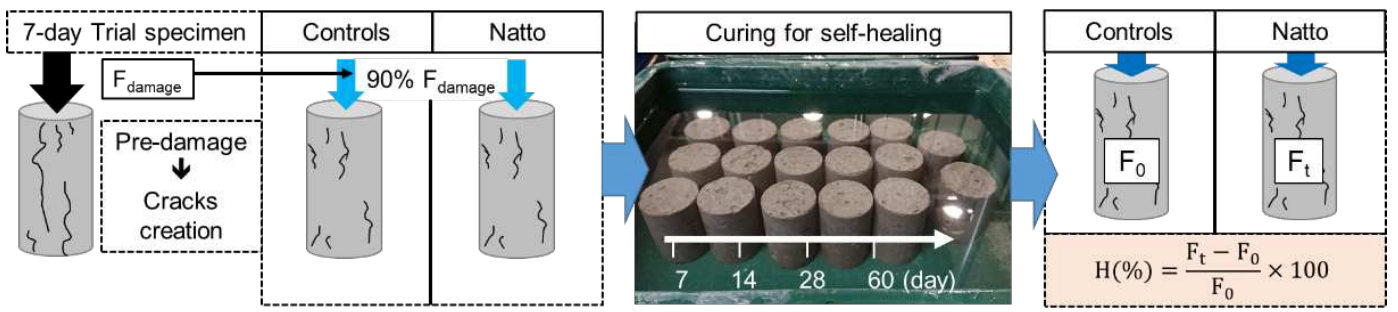

Figure 1. Flow chart for the preparation of lightweight aggregate immobilized bacteria and the continuous strength recovery test.

Table 1 shows the mixture proportion for concrete specimens $(\Phi=50 \mathrm{~mm}, \mathrm{H}=100 \mathrm{~mm})$. The lightweight aggregate $\left(\rho=1.68 \mathrm{~g} / \mathrm{cm}^{3}\right.$, water absorption $=29.5 \%$, ) immoblized bacteria was prepared as following steps: (i) mixed and stirred the bacterial solution ( $\mathrm{m}_{\text {urea }}=0.45$ $\% \mathrm{~m}_{\text {cement }}$, mbacteria $\leq 0.5 \% \mathrm{~m}_{\text {cement }}, \mathrm{m}_{\mathrm{CaCl} 2}=0.45 \% \mathrm{mc}_{\text {ement }}$ ); (ii) immersed the LWA in solution 
for 24 hours; (iii) dried the LWA at $40{ }^{\circ} \mathrm{C}$ for 24 hours. Based on the bacterial concentration in the mixture for $1 \mathrm{~m}^{3}$ of concrete $\left(1.1 \times 10^{12} \mathrm{CFU} / \mathrm{m}^{3}\right)$, the bacterial concentration for each specimen was calculated and estimated to $3 \times 10^{7} \mathrm{CFU}$. Also, the dosage of urea and $\mathrm{CaCl}_{2}$ was controlled with a safety limit according to ACI 318 for maximum chloride ion content in concrete to prevent the corrosion of reinforcement. For the group "Controls", the lightweight aggregate without bacteria was used as the reference. Figure 1 describes the flow chart of the continuous compressive strength improvement test. The load was defined based on the 7-day compressive strength of the "trial-specimen" with the mixture as the controlled. We used the value of $90 \%$ of this value $\left(F_{\text {Damage }}=11 \mathrm{~N} / \mathrm{mm}^{2}\right.$, loading rate $\left.=1.17 \mathrm{kN} / \mathrm{s}\right)$ to create the crack for all of the specimens. The self-healing effect was expected to occur over curing time. The compressive strength was measured after each curing period of 7 days, 14 days, 28 days, and 60 days to compare with the controls for healing capacity calculation. The recovery of the compressive strength of concrete specimens can translate into the self-healing efficiency, and then gives information about the relation between self-healing capacity and curing time.

\subsection{Water Permeability of Concrete Using Bacterial Lightweight Aggregate}

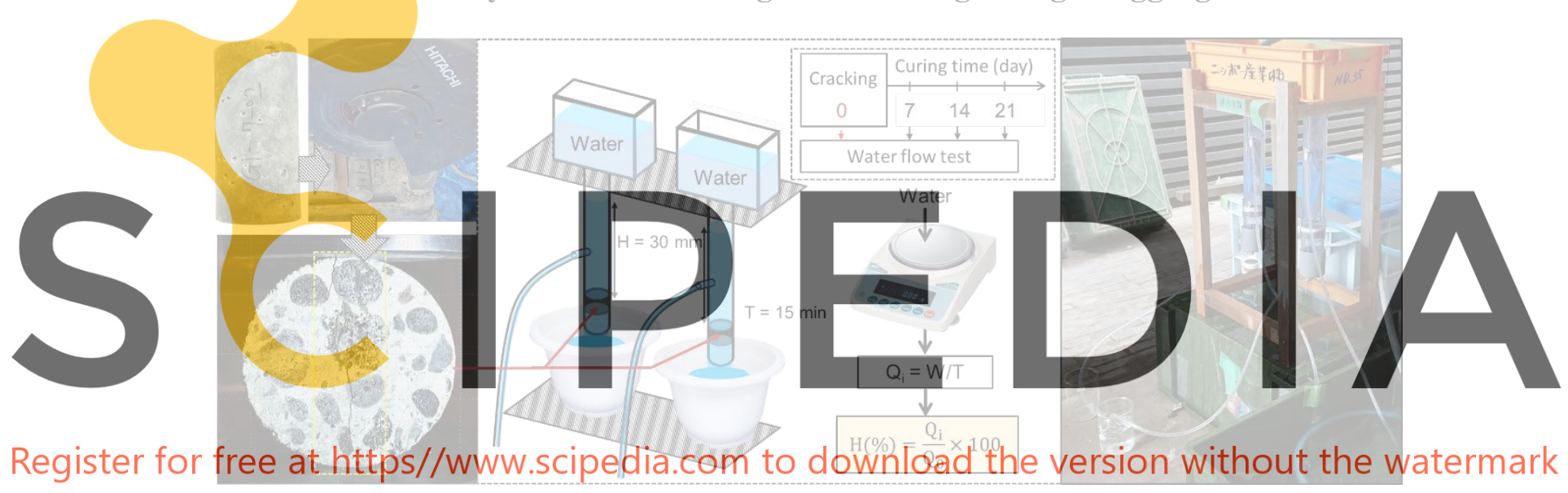

Figure 2. Flow chart for the water-flow test.

In both the cases of using capsule/microcapsule or vascular-based systems, capillary flow through discrete cracks is the primary mechanism (Gardner et al., 2017) for healing agents transporting in cement/mortar to damaged position and create the self-healing effect. Besides, the interaction between the healing fluid, in this case, is $\mathrm{CaCO}_{3}$, and the matrix is rough and more complex than the fluid mechanical theoretical behavior. Therefore, as the description in Figure 2, the test system for evaluating the self-healing effect on water permeability was investigated. The 14-day concrete specimens (mixture as Table 1) were cut into slices $(\Phi=50$ $\mathrm{mm}, \mathrm{T}=30 \mathrm{~mm}$ ) and then cracked under the splitting test. The crack width was measured by using an optical microscope. In the testing system, a continuous water flow with the water head of $30 \mathrm{~mm}$ was applied in 15 minutes. The water flow was measured after 7, 14, and 21 days of curing. The Hagen-Poiseuille's law was also used to compare and analyze the change of water flow and crack width under the healing effect. Based on the Hagen-Poiseuille's law, we calculated the water flow after 7 days and 28 days with the crack width by microscope observation. Then, we made the ratio of these values to the initial water flow $\left(\mathrm{QT}_{\mathrm{T}}\right)$. With the 
same method, we made the ratio of measurement value (QM). A comparison between the theoretical value and measured value in the experiment was expected to show the structural changes within the cracks, including crack width and crack depth. Also, one group of $1 \mathrm{~mm}-$ crack concrete slice was prepared to clarify the mechanism of the effect of biomineralization on the crack healing and reinforcing ability. These specimens were injected by commercial $\mathrm{CaCO}_{3}$ paste $\left(\mathrm{CaCO}_{3}\right.$ powder and water) and then measured the water flow. The difference between the bonding of concrete substrates and minerals provided from outside and forming in the cracks can demonstrate the bacterial self-healing ability.

\section{Results and Discussion}

\subsection{Compressive Strength Improvement Using Bacterial Lightweight Aggregate}

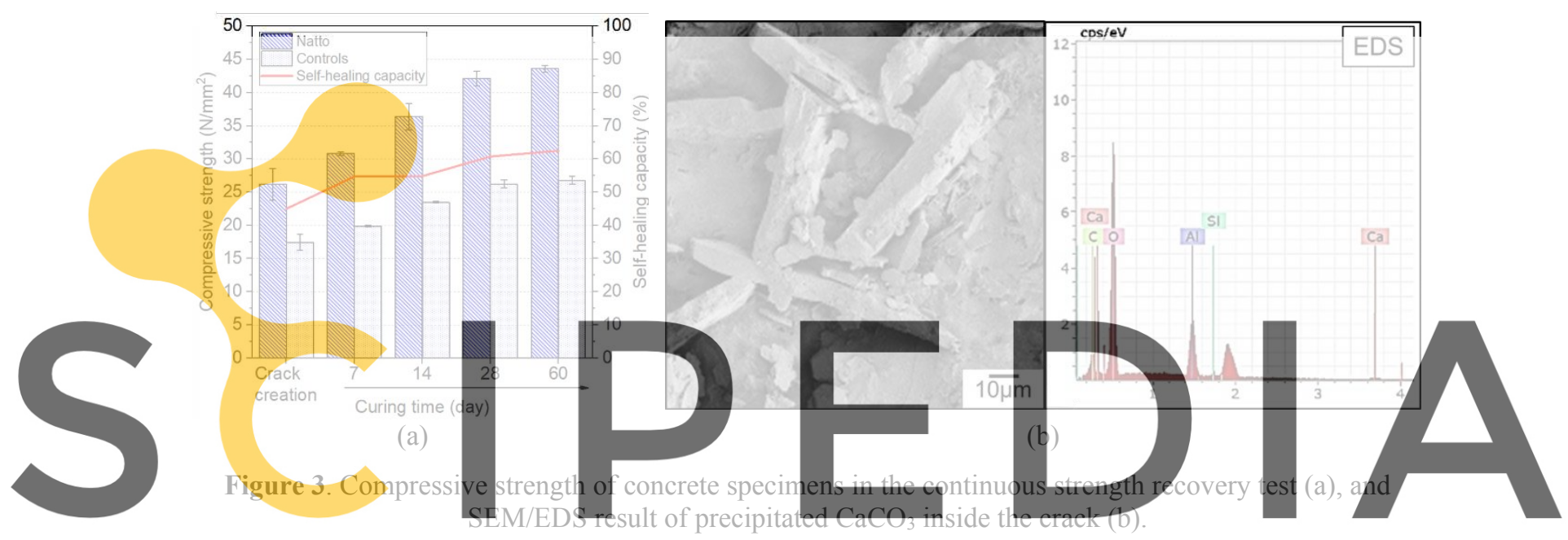

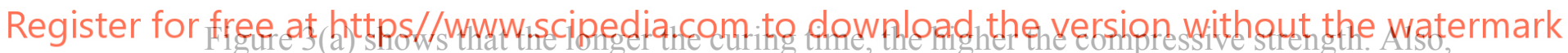
the compressive strength of the group "Natto" was significantly higher than the "Controls" at every period. This difference could be caused by the seif-healing effect with the capacity of over $40 \%$ just after 7 days curing before the cracking day. This result is higher than the previous study in 2017 (20\%) when using Bacillus subtilis JC3 (Rao et al., 2017) directly with a concentration of $10^{5} \mathrm{CFU} / \mathrm{ml}$ as mixing water; and the study in 2015 (Sarkar et al., 2015) using Bacillus subtilis with tryptone (16.6\%). Therefore, the immobilization of bacteria and nutrients in lightweight aggregate could not only prevent the disruption of concrete with the presence of organic matter but also fill the cracks and densify the pore structure. Besides, with this technique, the higher initial concentration of bacteria can be used for a longer duration and higher healing capacity. Moreover, from the 14-day curing period, the gap of compressive strength between the group "Natto" and "Controls" became higher. This result was relevant in the self-healing process with the increasing of $\mathrm{CaCO}_{3}$ over time.

As expected, Figure 3(b) shows a massive amount of $\mathrm{CaCO}_{3}$ formed inside the cracks by the biomineralization of Bacillus subtilis natto after 28 days. According to SEM observation, the shape of $\mathrm{CaCO}_{3}$ crystals was similar to the finding of the study using Sporosarcina pasteurrii bacteria (Ameri et al., 2019). These rod-shaped crystals could be a reinforced component in 
cracks, similar to the strength improvement mechanism of cementitious composite through whisker $\mathrm{CaCO}_{3}$ (Cao et al., 2019). Also, the forming of $\mathrm{CaCO}_{3}$ in the pores of concrete structure could densify the matrix contributes to the high compressive strength.

\subsection{Water Permeability of Concrete Using Bacterial Lightweight Aggregate}

Figure 4 shows the decrease of water flow with a decrease of crack width after three measurements. Under microscopic observation, the crack width range became smaller and smaller since the first test (Figure 4(a)). In contrast, the controlled specimens show a nearly constant result of water flow (Figure 4(b)) and a slightly reduced crack width. Note that the $0.10 \mathrm{~mm}$ or smaller cracks in the controlled specimens can be regarded as smooth and can be closed by the natural self-healing process by late hydration and the reaction of $\mathrm{Ca}(\mathrm{OH})_{2}$ with $\mathrm{CO}_{2}$. These results can be observed in both cases of test specimens with high correspond between $\mathrm{Q}_{\mathrm{T}}$ and $\mathrm{Q}_{\mathrm{M}}$. For the large-sized cracks, it can be seen the increase of crack closing by the decrease of water flow over curing time by the biomineralization (Figure 5(a)). In contrast, the controls show the higher value of $\mathrm{Q}_{\mathrm{M}}$ than $\mathrm{Q}_{\mathrm{T}}$ after 28 days as a result of the opening inside the cracks with damage by water flow (Figure 5(b)). Also, the significant reduction of measured water flow in the case of bacterial specimens (Figure 5(c)) indicated that the cracks were healed from the internal subsurface. This result was confirmed by the optical microscopic analysis of the crack depth (Figure 5(d)).

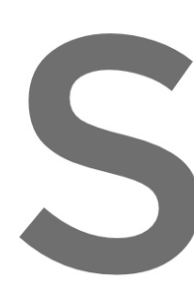

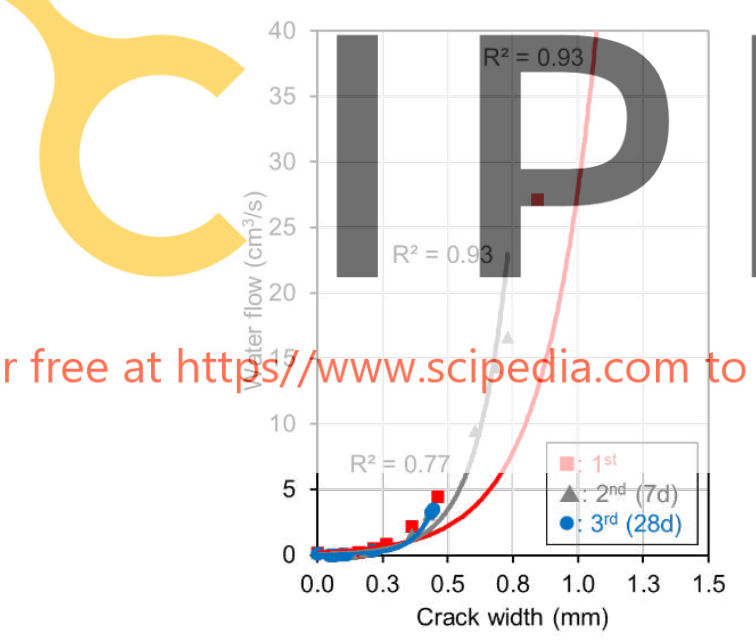

(a)

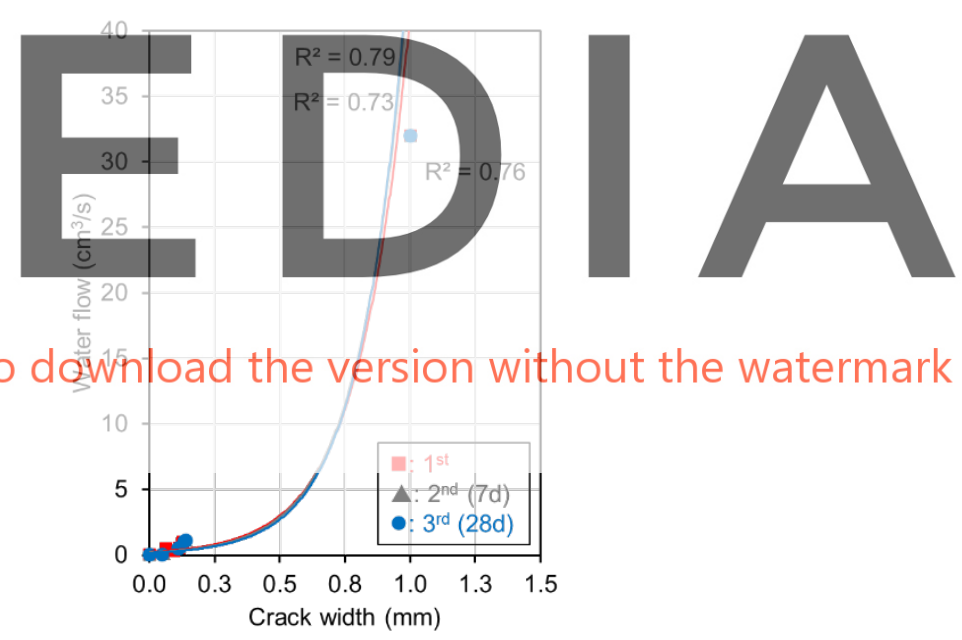

(b)

Figure 4. Water flow-crack width relationship after curing time of bacterial specimens (a), and the controls (b).

It can be seen that although water could pass through the specimen, the microscopic images (Figure 6(a)) show that surface crack over $1.5 \mathrm{~mm}$ could be healed almost $100 \%$ after 21 days of curing. Note that in the case of controlled specimens, cracks could only be healed within the maximum width of $0.1 \mathrm{~mm}$ by the late hydration effect. This result demonstrates that not only the internal subsurface but also the surface cracks could be healed with a high capacity over curing time. 

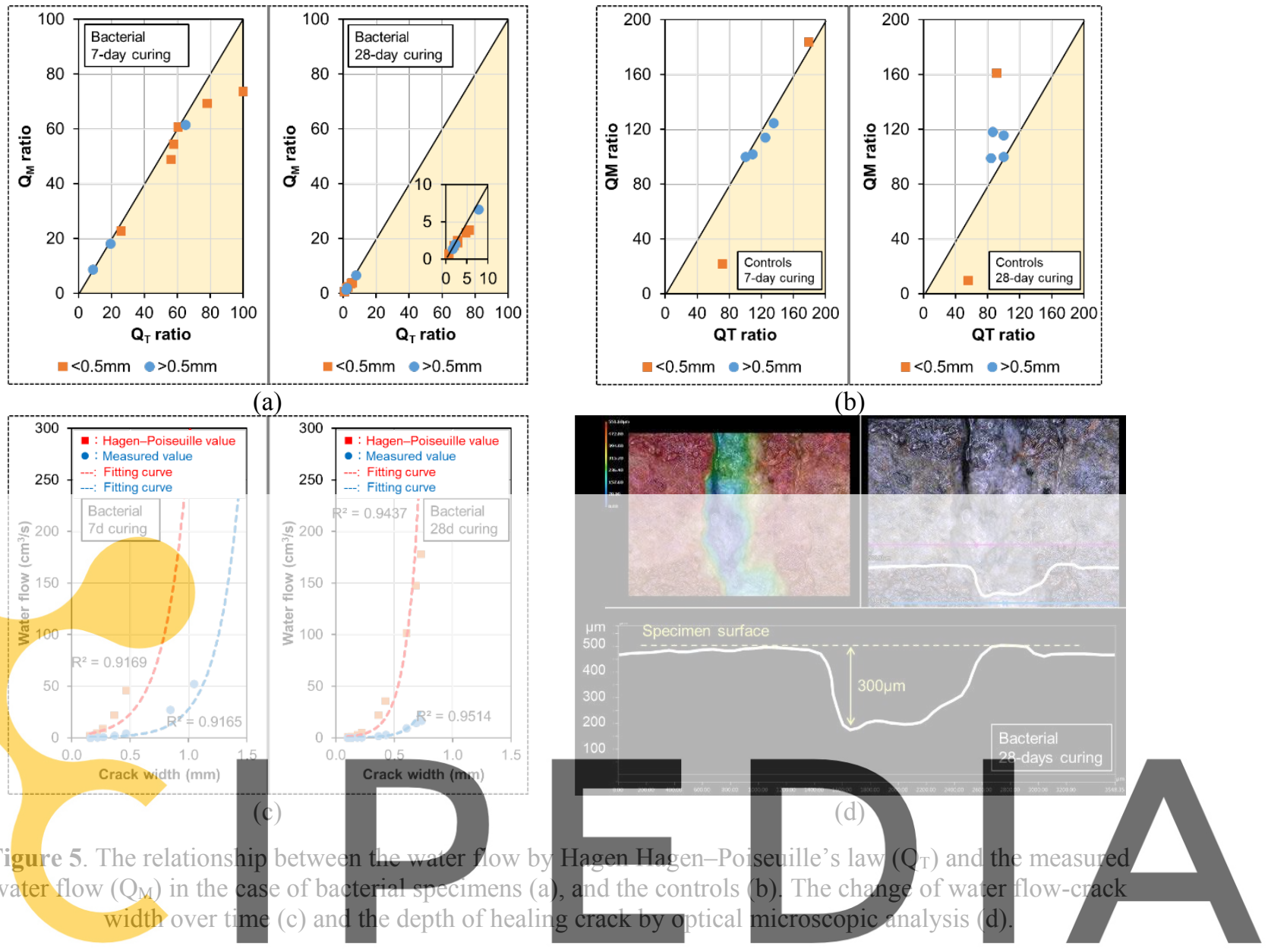

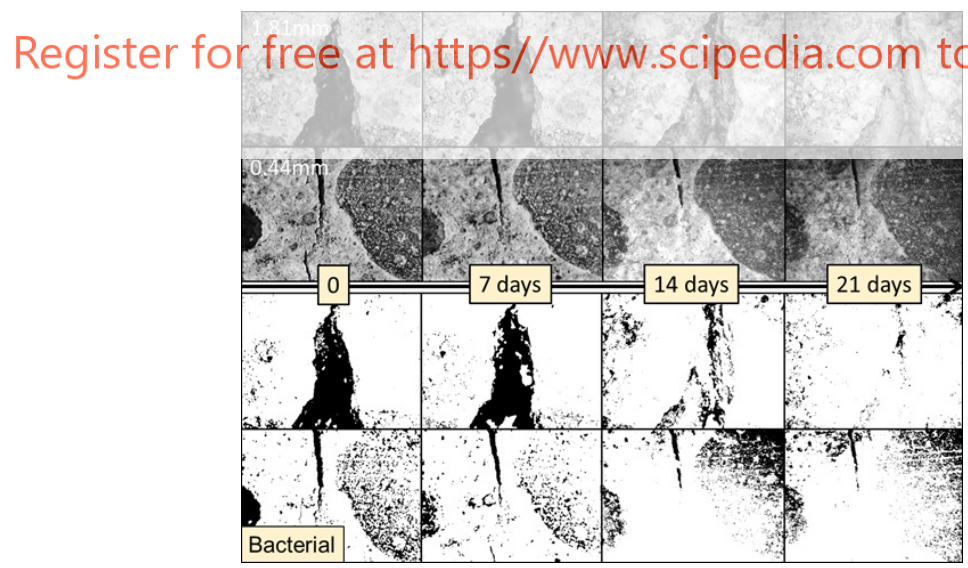

(a)

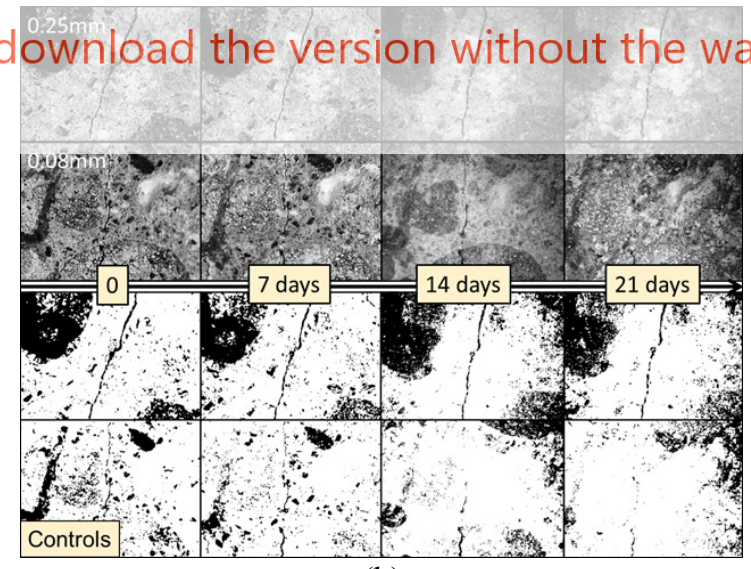

(b)

Figure 6. Crack width reduction over curing time in the case of bacterial specimens (a), and the controls (b).

Focus on the $1 \mathrm{~mm}$-crack case; it can be seen the mechanism of $\mathrm{CaCO}_{3}$ forming inside the crack by the activation of bacteria. The result of injected-CaCO 3 into the crack shows the significant low effectiveness on prevention water from passing to the upper face of the concrete 
slice. This consequence is closely related to the bond between the concrete substrate and the $\mathrm{CaCO}_{3}$ inserted into the crack. Harden concrete after setting period apparently cannot connect paste of $\mathrm{CaCO}_{3}$ by chemical reaction. In this case, only physical force as friction played the role of glue the two surfaces. This temporary cohesiveness decease with the removing of water in the paste. Hence, after natural drying, concrete substrate and injected-CaCO 3 separated almost, and immediately be washed away from the crack. Note that a small part of $\mathrm{CaCO}_{3}$ could be adhesive, particularly on the rough surface of the concrete crack. Although this phenomenon occurred nearly in the volume of $40 \%$ of the total crack volume, a considerable amount of water was interrupted from continuously flowing (Figure 7(b)). This result indicates that large amounts of $\mathrm{CaCO}_{3}$, especially rod-like crystals, as well as strong bonding to the concrete surface, can be an effective healing agent for waterproofing targets. Overall, therefore, the reducing of water flow over curing time in the case of using bacteria could be demonstrated clearly. The continuous water flows with $20 \mathrm{~mm}$ in height helped to remove the dust, sand, or broken piece of the concrete specimen from the crack position. Also, water pressure was enough to break down any weak bonding between concrete broken surfaces, and organic or inorganic matter potentially appeared. Rod-like $\mathrm{CaCO}_{3}$ crystals precipitated layer by layer under the biomineralization of Bacillus subtilis natto may not only fill out the crack but also reinforce the damaged structure.
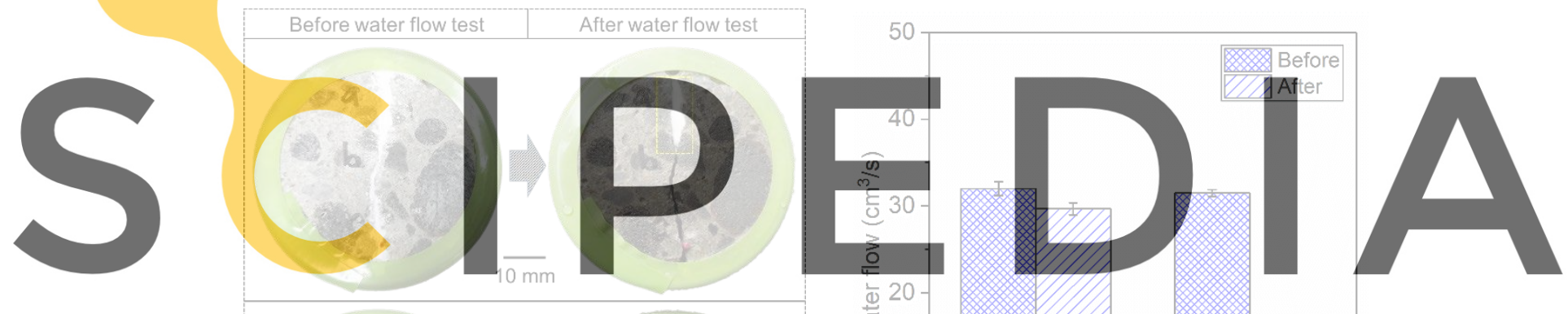

Register for free at https//www.scipedia.com to dowّ̋nlod the xersion withowthe watermark

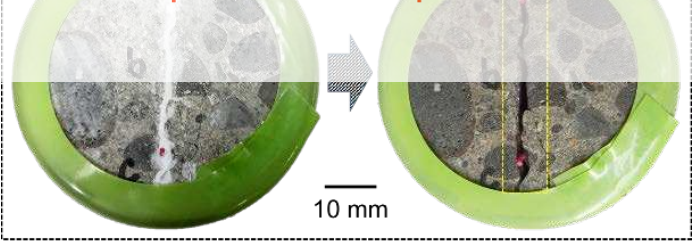

(a)

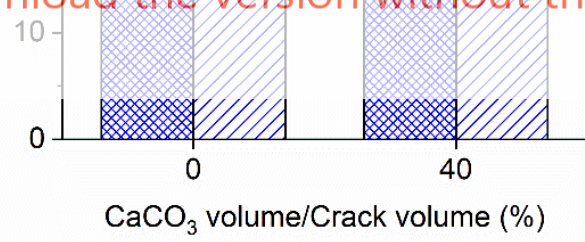

(b)

Figure 7. The camera photos of injected- $\mathrm{CaCO}_{3}$ specimens surface before and after the water flow test (a).

The relation between the water flow of injected- $\mathrm{CaCO}_{3}$ specimen and the estimating volume ratio (b).

\section{Conclusion}

Experimental results in this study indicate the following concluding remarks:

- Compressive strength after cracking could be improved in the case of using lightweight aggregate immobilized bacteria in the mixture. The healing capacity increased over curing time with the increasing of compressive strength.

- The massive amount of self-healing products could be observed by using SEM/EDS, and optical microscopic images played an essential role in closing the cracks and 
densifying the concrete structure.

- The water permeability of specimens using lightweight aggregate immobilized bacteria was significant lower than the controls. Healing capacity increased with the decrease of water flow through cracks over curing time.

- Surface cracks around $1.5 \mathrm{~mm}$ could be healed after 21 days, while the internal cracks were closed little by little over curing time.

\section{Acknowledgements (optional)}

The authors would like to appreciate the Japanese Government through the MEXT Scholarship and Building Material Science IMAMOTO LAB, Biology Science SHIMIZU LAB - Tokyo University of Science for financial supporting, materials and technical equipment.

\section{ORCID}

Ngoc Tri Huynh Nguyen: https://orcid.org/0000-0003-2085-3564

References

Ameri, F., Shoaei, P., Bahrami, N., Vaezi, M. and Ozbakkaloglu, T. (2019). Optimum rice husk ash content and bacterial concentration in self-compacting concrete. Construction and Building Materials, 222, 796-813.

Brenner, S. and Miller, J. H. (2014). Brenner's encyclopedia of genetics. Elsevier Science.

Cao, M., Li, L., Yin, H. and Ming, X. (2019). Microstructure and Strength of Calcium Carbonate (CaCO3) Whisker Reinforced Cement Paste After Exposed to High Temperatures. Fire Technology, 1-21.

Gardner, D., Herbert, D., Jayaprakash, M., Jefferson, A. and Paul, A. (2017). Capillary flow characteristics of an

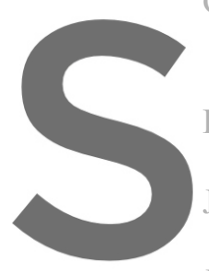
autogenic and Engineering, 29(

Huynh, N. N. T., Phuong, micropores of diato

Jonkers, H. M. (2007). S Springer.
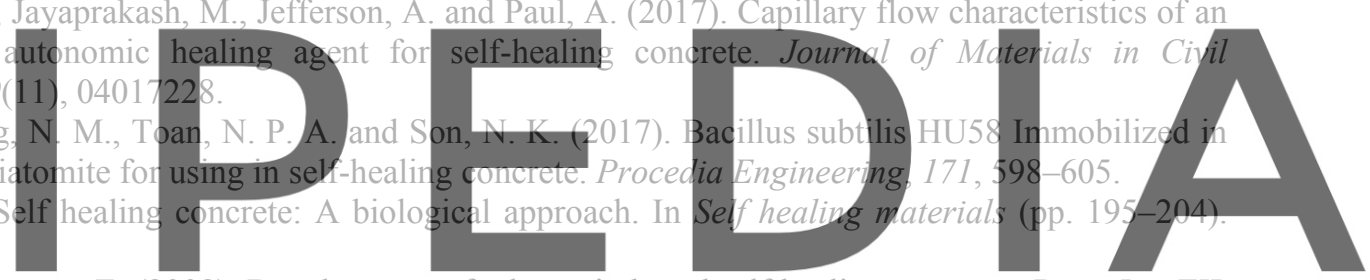

Jonkers, H. M. and Schlangen, E. (2008). Development of a bacteria-based self healing concrete. Proc. Int. FIB Symposium, 1, 425-430.

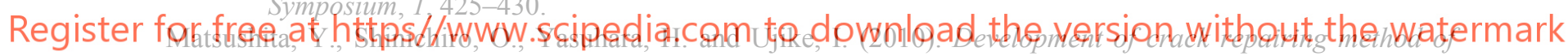
concrete using microbial metabolism. Vol.32(No.1).

Ramachandran, S. K., Ramakrishnan, V. and Bang, S. S. (2001). Remediation of concrete using micro-organisms. ACI Materials Journal-American Concrete Institute, 98(1), 3-9.

Rao, M. S., Reddy, V. S. and Sasikala, C. (2017). Performance of Microbial Concrete Developed Using Bacillus Subtilus JC3. Journal of The Institution of Engineers (India): Series A, 98(4), 501-510.

Sarkar, M., Adak, D., Tamang, A., Chattopadhyay, B. and Mandal, S. (2015). Genetically-enriched microbefacilitated self-healing concrete-a sustainable material for a new generation of construction technology. RSC Advances, 5(127), 105363-105371. 